Elisa Estenssoro

\title{
The FINNALI study on acute respiratory failure: not the final cut
}

Received: 16 May 2009

Accepted: 19 May 2009

Published online: 13 June 2009

(C) Springer-Verlag 2009

This editorial refers to the article available at:

doi:10.1007/s00134-009-1519-z.

E. Estenssoro (-

Intensive Care Unit, Hospital Interzonal de Agudos San Martin de La Plata, 42 No. 577, 1900 La Plata, Buenos Aires, Argentina

e-mail: elisaestenssoro@speedy.com.ar

Tel.: +54-2214220507

Fax: +54-2214790742

The authors of the FINNALI study, published in this issue of Intensive Care Medicine [1], are to be congratulated for a huge task: to describe the incidence and other epidemiological features of acute respiratory failure (ARF) in a whole country, Finland. As ARF is a frequent cause of admission to the ICU, it is surprising how few studies aim at characterising it [2-5]. Researchers have mainly focussed on the most severe forms of ARF: acute lung injury (ALI) and acute respiratory distress syndrome (ARDS) [6].

Some points deserve special comment: First, the incidence of 149.5 cases per 100,000/year is much higher than the 88.6 and 77.6 previously reported in prospective, population-based studies [2, 4]. This might be due to dissimilar definitions: the FINNALI investigators used a somehow "loose" definition of ARF: the need for ventilatory support with intubation, or the use of positive airway pressure for more than $6 \mathrm{~h}$. Instead, Lewandowski et al. [2] and Luhr et al. [4] defined ARF as the need for intubation and mechanical ventilation for more than $24 \mathrm{~h}$.
This last study, like the present FINNALI, also included patients with noninvasive ventilatory support. Behrendt et al., in the retrospective analysis of a large and representative US administrative database, found 137 cases per 100,000/year. Comparisons, again, are not easy, since they used ICD-9-CM codes for definition, plus continuous ventilatory support $\geq 24 \mathrm{~h}$. Interestingly, this study includes cases of ARF not restricted to the ICU. In real life, many ARF patients requiring ventilatory support might be treated in the ED and in general wards.

Even when the FINNALI investigators corrected their numbers for $24 \mathrm{~h}$, which yielded an incidence of 102.7 per 100,000/year, their figures seem to be high. Their main risk factor for ARF was postoperative state, similar to the International Study on Mechanical Ventilation [7], but doubling the frequency (41.3 vs. $20.8 \%$, respectively), contrasting with pneumonia as the main cause of ARF in the rest of the series [2, 4]. Prolonged duration of anaesthesia cannot be discarded as a cause of ARF in the FINNALI cohort. This is relevant, because in this era of rationing, these less severely affected patients might be admitted to intermediate-care units and not to the more complex and resource-consuming ICUs.

In epidemiological studies, seasonality should be taken into account. This study was performed in spring. It is usually held that airway and lung disease are more frequent in winter, and given that pneumonia is the most frequent clinical entity causing ARDS, the incidence might have been underestimated. There are some data, however, showing no differences in ARDS occurrence across different months [8].

What about ALI and ARDS, the most severe forms of ARF? Incidence was low: 10.6/5 cases of ALI/ARDS per $100,000 /$ year compared to $18 / 13.5$ in three Scandinavian countries [4], to 34/28, respectively, in three Australian states [9], or to 79/59 in King County, USA [10]. The authors wonder about a diminished, yet not demonstrated [11], genetic propensity for ALI in Finland. Furthermore, 
a decreased exposure to some risk factor might play a role: for example, trauma was a risk factor in only $1.5 \%$ of ALI/ARDS, probably due to organisational characteristics of Finnish society. However, some chance of misclassification, and so of a difference in incidences, cannot be discarded: the median $\mathrm{PaO}_{2} / \mathrm{FIO}_{2}$ of the nonALI/ARDS group is $\leq 300$ [272 (189-352)].

With respect to outcomes, two points are interesting: first, the choice of 90-day mortality as the main outcome measure, in line with adopting novel outcome variables for critical care; second, the report of previous health state by means of the ADL scale. Ninety-day mortality for ARF was $31 \%$, lying within the $31-42 \%$ reported in the literature $[2-5,7]$; as many as $48.4 \%$ of patients had some disability on admission. The figure of $47 \%$ mortality for ALI/ARDS falls within the expected $39-60 \%$ of epidemiological studies $[4,7,10,12,13]$. Once more, severity of illness on admission according to SAPS II, chronic heart disease, suspected aspiration and baseline $\mathrm{PaO}_{2} / \mathrm{FIO}_{2}$ were independently associated with a worse outcome. These factors have been repeatedly found $[12,14]$. Of note, this is another study demonstrating that the subset of patients with the worst $\mathrm{PaO}_{2} / \mathrm{FIO}_{2}$ values displays the highest mortality $[4,15,16]$. Perhaps future definitions of ALI/ ARDS will have to consider this special population.

Another interesting point lies in the use of tidal volumes. Notwithstanding that this study was undertaken many years after the publication of the ARMA study [17], tidal volumes used were $7.4 \mathrm{ml} / \mathrm{kg}$ actual body weight $(\mathrm{ABW})$ and indeed of $8.7 \mathrm{ml} / \mathrm{kg}$ of predicted body weight
(PBW). These numbers are certainly higher than the $6.2 \mathrm{ml} / \mathrm{kg}$ of PBW that demonstrated a survival benefit [17]. Moreover, and not surprisingly, the difference between ABW and PBW weight was larger in women, who were thus ventilated with $9.6 \mathrm{ml} / \mathrm{kg} \mathrm{PBW}$.

Two reflections arise from these findings that cast doubt on the efficacy of translating research into clinical practice [18]: First, why didn't these high tidal volumes impact mortality? A possible reason might be that patients in the FINNALI study were not severely compromised: though non-ALI/ARDS and ALI/ARDS groups showed a decrease in oxygenation (mean $\mathrm{PaO}_{2} / \mathrm{FIO}_{2} 272$ and 200, respectively), their mean plateau pressures were in fact low: 19 and $23 \mathrm{cmH}_{2} \mathrm{O}$, respectively. Hager et al. [19] have shown that the survival benefit of diminishing plateau pressure is clear and statistically significant only in the quartile of highest plateau pressures.

Finally, is the calculation of PBW systematically performed in real practice? The findings of this study raise concerns about this relevant issue, given that higher than physiological tidal volumes have been associated with the development of ARDS in patients on mechanical ventilation for causes other than ARDS [20].

To conclude, this study, together with the others mentioned, contributes to the overall picture of ARF around the world. But the face of ARF will probably keep on changing in incidence, in risk factors, in outcomes or in all together. There will never be a final cut. The forthcoming pandemic of swine flu is one example of how dynamic future scenarios might develop.

\section{References}

1. Linko R, Okkonen M, Pettilä V, Perttilä J, Parviainen I, Ruokonen E, Tenhunen J, Ala-Kokko T, Varpula T. The FINNALIstudy group (2009). Acute respiratory failure in intensive care units. FINNALI: a prospective cohort study. Intensive Care Med. doi:10.1007/s00134-0091519-Z

2. Lewandowski K, Metz J, Deutschmann C, Preiss H, Kuhlen R, Artigas A, Falke KJ (1995) Incidence, severity, and mortality of acute respiratory failure in Berlin, Germany. Am J Respir Crit Care Med 151:1121-1125

3. Behrendt CE (2000) Acute respiratory failure in the United States: incidence and 31-day survival. Chest 118:11001115

4. Luhr OR, Antonsen K, Karlsson M, Aardal S, Thorsteinsson A, Frostell CG, Bonde J (1999) Incidence and mortality after acute respiratory failure and acute respiratory distress syndrome in Sweden, Denmark, and Iceland. Am J Respir Crit Care Med 159:1849-1861
5. Vincent JL, Akça S, De Mendonça A, Haji-Michael P, Sprung C, Moreno R, Antonelli M, Suter PM, SOFA Working Group. Sequntial organ failure assessment (2002) The epidemiology of acute respiratory failure in critically ill patients. Chest 121:1602-1609

6. Bernard G, Artigas A, Brigham K, Carlet J, Falke K, Hudson L, Lamy M, Legall J, Morris A, Spragg R (1994)

The American-European Consensus Conference on ARDS. Definitions, mechanisms, relevant outcomes, and clinical trial coordination. Am J Respir Crit Care Med 149:818-824

7. Esteban A, Anzueto A, Frutos F, Alía I, Brochard L, Stewart TE, Benito S, Epstein SK, Apezteguía C, Nightingale P, Arroliga AC, Tobin MJ (2002) Mechanical Ventilation International Study Group characteristics and outcomes in adult patients receiving mechanical ventilation: a 28-day international study. JAMA 287:345355
8. Arroliga AC, Ghamra ZW, Perez Trepichio A, Perez Trepichio P, Komara JJ Jr, Smith A, Wiedemann HP (2002) Incidence of ARDS in an adult population of northeast Ohio. Chest 121:1972-1976

9. Bersten AD, Edibam C, Hunt T, Moran J, Australian, New Zealand Intensive Care Society Clinical Trials Group (2002) Incidence and mortality of acute lung injury and the acute respiratory distress syndrome in three Australian States. Am J Respir Crit Care Med 165:443-448

10. Rubenfeld GD, Caldwell E, Peabody E, Weaver J, Martin DP, Neff M, Stern EJ, Hudson LD (2005) Incidence and outcomes of acute lung injury. N Engl J Med 353:1685-1693

11. Barnes KC (2005) Genetic determinants and ethnic disparities in sepsisassociated acute lung injury. Proc Am Thorac Soc 2:195-201 
12. Estenssoro E, Dubin A, Laffaire E, Canales H, Sáenz G, Moseinco M, Pozo M, Gómez A, Baredes N, Jannello G, Osatnik J (2002) Incidence, clinical course, and outcome in 217 patients with acute respiratory distress syndrome. Crit Care Med 30:24502456

13. Brun-Buisson C, Minelli C, Bertolini G, Brazzi L, Pimentel J, Lewandowski K, Bion J, Romand JA, Villar J, Thorsteinsson A, Damas P, Armaganidis A, Lemaire F (2004) ALIVE Study Group Epidemiology and outcome of acute lung injury in European intensive care units. Results from the ALIVE study. Intensive Care Med 30:51-61

14. Ware LB (2005) Prognostic determinants of acute respiratory distress syndrome in adults: impact on clinical trial design. Crit Care Med 33:S217-S222

15. Gattinoni L, Tognoni G, Pesenti A, Taccone P, Mascheroni D, Labarta V, Malacrida R, Di Giulio P, Fumagalli R, Pelosi P, Brazzi L, Latini R, ProneSupine Study Group (2001) Effect of prone positioning on the survival of patients with acute respiratory failure. N Engl J Med 345:568-573
16. Mercat A, Richard JC, Vielle B, Jaber S, Osman D, Diehl JL, Lefrant JY, Prat G, Richecoeur J, Nieszkowska A, Gervais C, Baudot J, Bouadma L, Brochard L, Expiratory Pressure (Express) Study Group (2008) Positive end-expiratory pressure setting in adults with acute lung injury and acute respiratory distress syndrome: a randomized controlled trial. JAMA 299:646-655

17. The Acute Respiratory Distress Syndrome Network (2000) Ventilation with lower tidal volumes as compared with traditional tidal volumes for acute lung injury and the acute respiratory distress syndrome. N Engl J Med 342:1301-1308

18. Young MP, Manning HL, Wilson DL, Mette SA, Riker RR, Leiter JC, Liu SK, Bates JT, Parsons PE (2004) Ventilation of patients with acute lung injury and acute respiratory distress syndrome: has new evidence changed clinical practice? Crit Care Med 32:1260-1265
19. Hager DN, Krishnan JA, Hayden DL, Brower RG, ARDS Clinical Trials Network (2005) Tidal volume reduction in patients with acute lung injury when plateau pressures are not high. Am J Respir Crit Care Med 172:1241-1245

20. Schultz MJ, Haitsma JJ, Slutsky AS, Gajic O (2007) What tidal volumes should be used in patients without acute lung injury? Anesthesiology 106:12261231 